\title{
Water Use of Two Landscape Tree Species in Tucson, Arizona
}

\author{
D.G. Levitt ${ }^{1}$ \\ Department of Soil and Water Science, University of Arizona, Tucson, AZ 85721
}

J.R. Simpson ${ }^{2}$

Western Center for Urban Forest Research, U.S. Forest Service, Department of Environmental Horticulture, University of California, Davis, CA 95616

\author{
J.L. Tipton ${ }^{3}$ \\ Department of Plant Sciences, University of Arizona, Tucson, AZ 85721
}

\begin{abstract}
Additional index words. Argentine mesquite, Prosopis alba, live oak, Quercus viginiana, water use, Penman equation Abstract. Although water conservation programs in the arid southwestern United States have prompted prudent landscaping practices such as planting low water use trees, there is little data on the actual water use of most species. The purpose of this study was to determine the actual water use of two common landscape tree species in Tucson, Ariz., and water use coefficients for two tree species based on the crop coefficient concept. Water use of oak (Quercus virginiana 'Heritage') and mesquite (Prosopis alba 'Colorado') trees in containers was measured from July to October 1991 using a precision balance. Water-use coefficients for each tree species were calculated as the ratio of measured water use per total leaf area or per projected canopy area to reference evapotranspiration obtained from a modified FAO Penman equation. After accounting for tree growth, water-use coefficients on a total leaf area basis were 0.5 and 1.0 for oak and mesquite, respectively, and on a projected canopy area basis were 1.4 and 1.6 for oaks and mesquites, respectively. These coefficients indicate that mesquites (normally considered xeric trees) use more water than oaks (normally considered mesic trees) under nonlimiting conditions.
\end{abstract}

There is little information on the water use and requirements of isolated landscape trees. Most of the information on tree water use in the southwest is based on low-water-use trees recommended by various organizations (e. g., Arizona Municipal Water Users Association, Arizona Native Plant Society, Southern Arizona Water Resources Association) and reported in some literature (Desai, 198 1; McGinnies and Arnold, 1939). Lists of these trees are usually based on empirical observations and the plant's native habitat, due to the lack of data on actual tree water use. They are also largely based on observations of minimum water requirements and drought survivability, rather than actual water use. Therefore, some drought-resistant tree species on these lists may actually be moderate or high water users when water is nonlimiting. Mesquite (Prosopis var.), for example, is known to be drought resistant, but its actual water use is not known.

Methods for estimating water use of isolated trees consist of direct measurement, such as by lysimeter (Fritschen et al., 1977); soil water balance (Grip et al., 1979); chamber (Leuning and Foster, 1990); and heat-pulse or heat-balance (Steinberg et al., 1989) methods, Some models have also been developed for the indirect measure of tree water use based on reference crop evapotranspiration and the tree energy balance (Worthington et al., 1984). Most of the models developed for predicting water use of an isolated tree are based on the Penman-Monteith (PM) equation and require surface and aerodynamic resistance terms, which are often difficult to obtain (Monteith, 1965). There are many studies that use the PM equation to predict isolated tree water use, with varying degrees of success (Denmead, 1984; Landsberg and McMurtie, 1984).

Although these methods may accurately estimate water use of

Received for publication 16 June 1994, Accepted for publication 28 Nov. 1994. The cost of publishing this paper was defrayed in part by the payment of page charges, Under postal regulations, this paper therefore must be hereby marked advertisement solely to indicate this fact.

'Soil physicist.

${ }^{2}$ Urban forest researcher.

${ }^{3}$ Professor. isolated trees, their complexity and practicality varies considerably. A simple index based on tree species and related to climatological conditions would probably be more useful for homeowners, nurseries, landscape professionals, and the layman, in general. This type of an index has been used for quantifying crop water use. The dimensionless crop coefficient $\left(\mathrm{K}_{\mathrm{c}}\right)$ (Doorenbos and Pruitt, 1977 ) is calculated as the ratio of actual water use (ETa) to reference evapotranspiration (ETo), where water use is expressed as a depth of water evaporated per time for a well-watered, nonstressed crop:

$$
\mathrm{K}_{\mathrm{c}}=\frac{\mathrm{ET} \mathrm{a}}{\mathrm{ETo}}
$$

where ETa and ETo have units of mm.day ${ }^{-1}$. ETo estimates are meant to approximate the evapotranspiration from an extensive surface of 8 to $15 \mathrm{~cm}$ tall green grass cover of uniform height, actively growing, completely shading the ground and not short of water (Doorenbos and Pruitt, 1977). ETo is calculated using either a class A evaporation pan or one of the ETo equations, such as the FAO Penman equation (Doorenbos and Pruitt, 1977).

The concept of the dimensionless crop coefficient has been applied to orchards, where tree water use is defined as water use per projected canopy area and the orchard canopy is considered to be a uniform surface. Worthington et al. (1984) reported crop coefficients of 0.71 for peach trees, where water use was measured by weighing lysimeter, and ETo was based on class A evaporation pan data. Tan and Layne ( 198 1) reported coefficients of 0.85 for peach trees, where water use was based on soil moisture measurements and ETo was based on a simplified Priestley Taylor equation. Hoffman et al. ( 1982) reported crop coefficients of 0.75 to 0.85 for mature Valencia orange trees in an arid climate, where water use was based on leaching fraction and ETo was based on class A pan evaporation and several ETo equations. Middleton et al. (1979) reported crop coefficients of 0.02 to 0.2 for apple trees, where water use was measured by weighing lysimeter and ETo was based on class A pan evaporation. Snyder et al. (1989) reported crop 
coefficients for a variety of orchard species, as well as a general crop coefficient for trees of 1.20 , but they did not report their method of determining crop water use.

These applications of the crop coefficient concept to stands of trees, such as orchards, have been based on the assumption of onedimensional (1 -D) heat and vapor transport and that the orchard surface can be considered the same as a uniform crop surface. This assumption is only safe with adequate fetch and adequate sensor height above the orchard, and while this may be a safe assumption for stands of trees, it may not be for isolated trees. Heat and vapor transport for isolated trees is significantly more complex than the 1 -D transport for a crop surface. Net radiation, which has a stronger influence on Penman ETo than any other environmental parameter, is measured on a horizontal surface, and an isolated tree will intercept much more radiation than a horizontal surface. Also, the effects of wind on a 3-D surface such as an isolated tree are far less predictable than for an extensive crop.

Very little work has been reported in which crop coefficients are used to predict water use of heterogeneous surfaces. Costello et al. (1992) applied the crop coefficient concept to heterogeneous landscape applications using a landscape coefficient method $\left(\mathrm{K}_{\mathrm{L}}\right)$, where $\mathrm{K}_{\mathrm{L}}$ is the product of species, density, and microclimate factors. However, the $\mathrm{K}_{\mathrm{L}}$ method is not calculated from field measurements, The species, density, and microclimate factors are each qualitative approximations of the factors that affect water use in landscapes. Therefore, $\mathrm{K}_{\mathrm{L}}$ values are not directly comparable to crop coefficient values.

We know of only one study in which crop coefficients were calculated for actual isolated landscape trees: Garbesi (1992) reported that isolated landscape trees have maintained acceptable levels of growth and appearance at average crop coefficient values of $\approx 0.40$. However, Garbesi reported a crop coefficient for trees that were not well watered, therefore violating the definition of crop coefficient.

Applications of $\mathrm{KC}$ to stands of trees and isolated trees have been expressed as water use per projected canopy area (PCA). While this type of coefficient is useful for comparing values, the ratio of water use per total leaf area (TLA) would be more useful in landscaping scenarios because TLA is generally well correlated with air cooling, carbon dioxide reduction, and rainfall and dust interception (McPherson, 1991). TLA and PCA are related to tree leaf area index (LAI) by

$$
L A I=\frac{T L A}{P C A}
$$

where LAI is dimensionless, and TLA and PCA have units of $\mathrm{m}^{2}$. If any two of these three parameters are known, the third can be calculated.

Actual water use of a crop, where water is not limiting, soil evaporation is assumed to be minimal, and canopy cover is complete, was defined in Eq. [1] as ETa. Since the application of a crop coefficient to isolated trees does not include the soil evaporation component, it would be logical to refer to tree water use simply as transpiration (T) only instead of ETa, where T can be expressed on a TLA basis as $\mathrm{T}_{\mathrm{TLA}}$ and

$$
\mathrm{T}_{\mathrm{TLA}}=\frac{\mathrm{H}_{2} \mathrm{O}}{\mathrm{TLA}}
$$

where $\mathrm{T}_{\text {TLA }}$ has units of mm.day ${ }^{-1}, \mathrm{H}_{2} \mathrm{O}$ is daily water use in liters $\mathrm{H}_{2} \mathrm{O} /$ day, and TLA has units of $\mathrm{m}^{2}$. Similarly for tree water use on a PCA basis,

$$
\mathrm{T}_{\mathrm{PCA}}=\frac{\mathrm{H}_{2} \mathrm{O}}{\mathrm{PCA}}
$$

For the remainder of this paper, therefore, water-use coefficients for trees will be referred to as $\mathrm{K}_{\text {tree }}$, instead of $\mathrm{KC}$, where

$$
\mathrm{K}_{\text {tree }}=\frac{\mathrm{T}}{\mathrm{ET} \mathrm{O}}
$$

and $\mathrm{T}$ can be $\mathrm{T}_{\mathrm{TLA}}$ or $\mathrm{T}_{\mathrm{PCA}}$ for a well-watered tree.

The purpose of this study was 1) to determine, by weighing, the actual water use of two potted desert landscape tree species in Tucson, under nonlimiting water conditions and 2) to determine water-use coefficients $\left(\mathrm{K}_{\text {tree }}\right)$ for each tree species based on the crop coefficient concept.

\section{Materials and Methods}

The field experiment was conducted at the Univ. of Arizona Campus Agricultural Center (CAC) in Tucson, from 2 July to 23 Ott, 1991. Tucson $(32.3 \mathrm{~N}, 111 \mathrm{~W})$ lies at an elevation of $\approx 700 \mathrm{~m}$. The weather during the experiment was characterized by sunny, hot, dry days interspersed with occasional thunderstorms and warm nights. The average daily maximum temperature was $36.7 \mathrm{C}$ with little variation. The daily minimum temperature during the experiment ranged from $12.8 \mathrm{C}$ to $27.8 \mathrm{C}$.

The oak and mesquite trees used in the experiment were $\approx 20$ $\mathrm{mm}$ caliper (i.e., diameter at $0.5 \mathrm{~m}$ above the ground surface). Oaks were between 1.5 and $2.0 \mathrm{~m}$ in height and mesquites were $\approx 3 \mathrm{~m}$ in height. The oaks were planted directly in potting soil in 57-liter containers on 1 June 1991; the mesquites were planted in 19-liter containers until 9 July 1991, when they were transplanted to 57liter containers. Containers were wrapped in clear plastic to minimize soil evaporation. At each tree site, an empty 57-liter pot was buried up to its top edge to provide a sleeve for the potted trees. This allowed the potted soil surface to be at approximately the same level as the surrounding ground surface. Trees were located in a grid with a spacing between each tree of $4 \mathrm{~m}$. A total of 20 trees was used in the experiment. The ground surface between and surrounding the trees consisted of bare soil.

Daily tree water use was measured by weighing each containerized tree on an electronic precision balance (model EP-60KB; A\&D Engineering), which had a maximum capacity of $60 \mathrm{~kg}$ and a resolution of $1 \mathrm{~g}$. The weighing procedure consisted of lifting a potted tree out of its sleeve, placing it on a wheelbarrow, moving it to the balance located in the center of the field site, weighing the tree, then moving it back into its sleeve. The entire procedure took $\approx 40$ min to weigh 20 trees.

Several different schedules for weighing and irrigating the trees were tested during the experiment. From 2-9 July 1991 (calendar day (CD) 183-190), daily tree water use was determined and that exact amount of water was replaced using a graduated cylinder. During this period, the bottom of the tree pots were also sealed to prevent drainage. This procedure offered the advantage of requiring only one weighing to determine $24-\mathrm{h}$ water use. However, the lack of leaching of salts and lack of excess irrigation for plant growth resulted in the revision of this schedule. From 10-20 July 1991 (CD 19 1-201 ), the trees were irrigated from 2100-2300 HR, and the pots were weighed at $\approx 900$ and $2000 \mathrm{HR}$. Difficulty arose in translating the water use from 900-2000 HR measured by the balance, into more useful 24-h water use data for use in modeling transpiration.

From 22 July-1 Aug. 1991 (CD 203-2 13) and from 8-23 Sept. 1991 (CD 251 -266), a 3-day schedule was tested in which all trees 
were weighed at $2000 \mathrm{HR}$, irrigated from $2100-2300 \mathrm{HR}$ on the first day of a cycle and weighed at $\approx 0900$ HR on the second. On day 3, trees were weighed at $0900 \mathrm{HR}$, irrigated from 0900-1 $100 \mathrm{HR}$, allowed to drain until $2000 \mathrm{HR}$, then weighed again, at which time the cycle repeated. This schedule yielded an irrigation frequency of $36 \mathrm{~h}$, and 24-h water use data every $36 \mathrm{~h}$. It provided frequent water-use data, allowed drainage, and prevented the trees from becoming water stressed, but required considerable labor time in the field.

From 24 Sept.-23 Oct. 1991 (CD 267-296), the trees were irrigated at $2000 \mathrm{HR}$ on day 1, weighed at $900 \mathrm{HR}$ on day 2, weighed again at $900 \mathrm{HR}$ on day 3, and then irrigated at 1000 and $2000 \mathrm{HR}$ on day 3 . This schedule provided $24-\mathrm{h}$ water-use data every $48 \mathrm{~h}$ and an irrigation frequency of $36 \mathrm{~h}$. This schedule allowed drainage, was frequent enough that the trees did not become water stressed, required only one weighing per $24 \mathrm{~h}$, and was the preferred weighing-irrigation schedule overall. During each of these tested schedules, conditions were never found to be water limiting, as confirmed with tensiometers; therefore, changing irrigation schedules was not believed to affect the transpiration results.

TLA was determined using an empirical calibration between TLA and shoot length (Ceulemans et al., 1989). Shoot length and TLA of one oak and one mesquite was determined using a Decagon Image Analysis System (DIAS) in September 1991. The length of every shoot of each tree was measured, then the leaves from each shoot were removed for determination of leaf area. The mesquite tree used for the calibration had a 20-mm-diameter caliper and a total leaf area of $\approx 1.46 \mathrm{~m}^{2}$. A 20 -mm-diameter caliper oak with a total leaf area of $\approx 1.12 \mathrm{~m}^{2}$ was used for the oak calibration. For the oak, all shoots having a length $\geq 12 \mathrm{~cm}$ were measured. Shoot lengths shorter than $12 \mathrm{~cm}$ were not measured due to their quantity and the time-consuming nature of the measurements. Therefore, any leaves on shoots $<12 \mathrm{~cm}$ long were associated with their respective main shoots.

On 6 Nov. 1991, the projected canopy area (PCA) of each tree was measured by outlining the drip line of each tree canopy. Canopy drip lines were traced into the soil by use of a vertical rod, and the traced area on the soil surface was measured. For oak, the traced area was measured by assuming a circular area and measuring its diameter, and for mesquite, the area was measured by dividing each outlined area into $10 \times 10-\mathrm{cm}$ squares and summing their areas. LAI was then determined using Eq. [2].

Throughout the experiment, approximations of tree growth were made by periodically measuring the lengths of new shoot growth, and appropriate adjustments were then made on the estimates of TLA and PCA.

Dimensionless tree water-use coefficients were calculated using Eq. [5]. Daily reference evapotranspiration (ETo) was calculated using a modified Penman equation used by the Arizona Meteorological Network (AZMET):

$$
\mathrm{ETo}=\mathrm{W}(\mathrm{Rn})+(1-\mathrm{W})(\mathrm{VPD}) \mathrm{f}(\mathrm{U})
$$

where $\mathrm{Rn}=$ the net radiation in equivalent depth of water $(\mathrm{mm})$, $\mathrm{W}=\mathrm{a}$ dimensionless weighting function, $\mathrm{VPD}=$ the vapor pressure deficit $(\mathrm{kPa})$, and $\mathrm{f}(\mathrm{U})=$ an empirical wind function $\left(\mathrm{mm} \cdot \mathrm{kpa}^{-1}\right)$.

ETo data were collected at a weather station located in the center of the field site. Measurements of solar radiation, temperature, relative humidity, and wind speed (all sensors were located at $2 \mathrm{~m}$ ) were taken once each minute, averaged into 60-min values,

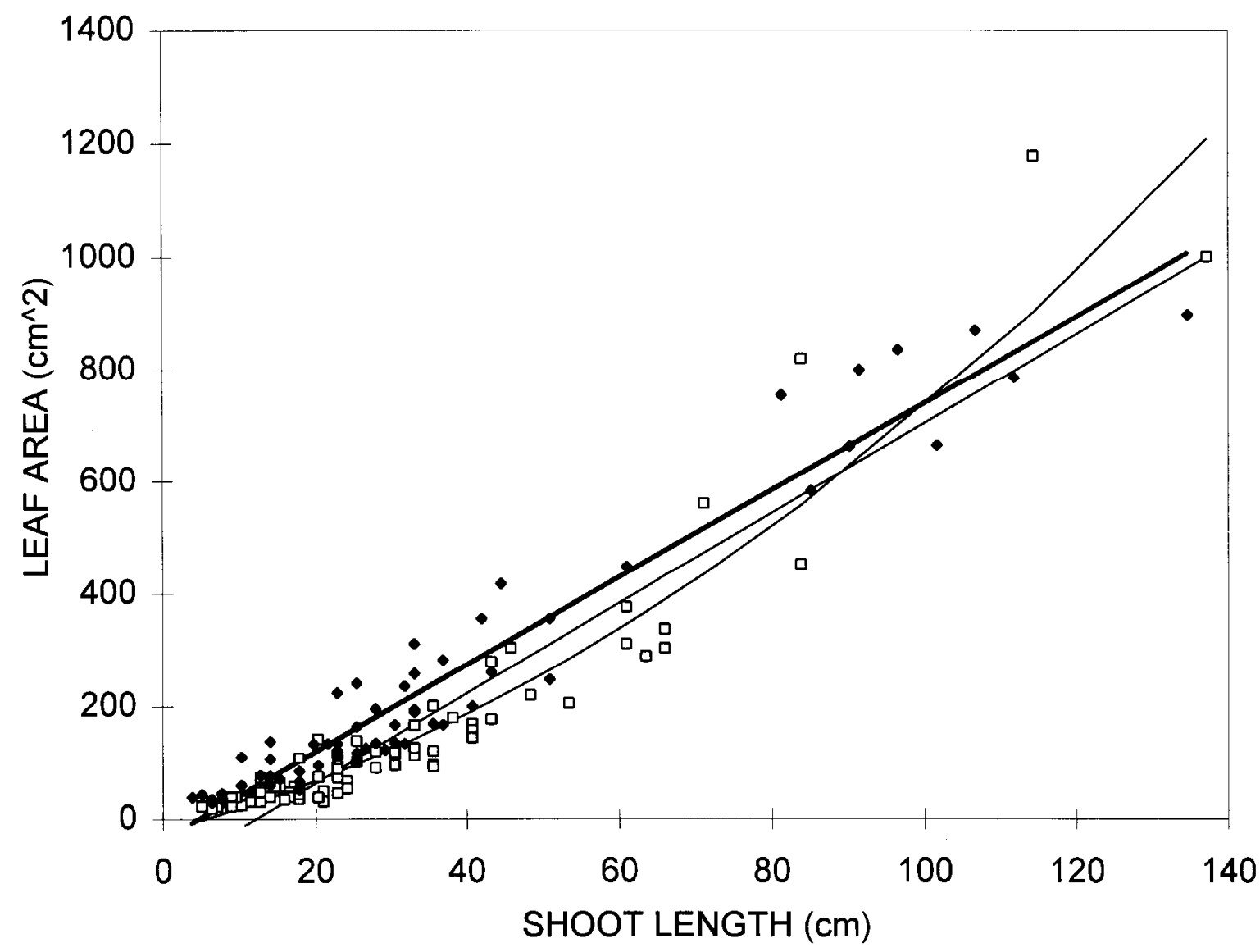

Fig. 1. Relationship of shoot length (SL) to leaf area (LA) for oak $(\square)$ and mesquite $(\bullet)$ ). Regression analysis for oak yielded: LA = 8.0 SL - 97; or LA $=3.6 \mathrm{SL}+0.03883 \mathrm{SL}^{2}-21$ (second order). Regression analysis for mesquite yielded: $\mathrm{LA}=7.8 \mathrm{SL}-36$. 
Table 1. Total leaf area, projected canopy area, and leaf area index for potted oak and mesquite trees.

\begin{tabular}{llccc}
\hline Tree ID & Species & TLA $\left(\mathrm{m}^{2}\right)$ & PCA $\left(\mathrm{m}^{2}\right)$ & LAI \\
\hline 1 & Oak & 1.13 & 0.37 & 3.0 \\
6 & & 1.05 & 0.49 & 2.1 \\
2 & & 0.92 & 0.41 & 2.2 \\
3 & & 0.85 & 0.52 & 1.6 \\
8 & & 0.62 & 0.13 & 4.8 \\
10 & & 0.49 & 0.13 & 3.8 \\
5 & & 0.45 & 0.12 & 3.7 \\
12 & & 0.42 & 0.15 & 2.9 \\
19 & Mesquite & 0.98 & 0.55 & 1.8 \\
17 & & 0.93 & 0.62 & 1.5 \\
15 & & 0.89 & 0.52 & 1.7 \\
20 & & 0.85 & 0.51 & 1.7 \\
18 & & 0.83 & 0.46 & 1.8 \\
16 & & 0.79 & 0.53 & 1.5 \\
4 & & 0.79 & 0.46 & 1.7 \\
14 & & 0.68 & 0.56 & 1.2 \\
7 & 0.66 & 0.54 & 1.2 \\
9 & & 0.65 & 0.34 & 1.9 \\
13 & 0.60 & 0.46 & 1.3 \\
11 & & 0.59 & 0.32 & 1.9 \\
\hline
\end{tabular}

and used to calculate hourly ETo. Daily ETo was calculated as the sum of 24 hourly ETo values.

Solar radiation (Rs) in MJ. $\mathrm{m}^{-2}$ was converted to net radiation $(\mathrm{Rn})$ in $\mathrm{W} \cdot \mathrm{m}^{-2}$ using the two following empirical equations:

$$
\mathrm{Rn}=\mathrm{Rs}(0.767)+[-0.17+0.056(\text { Es }-\mathrm{VPD})]
$$

Rs $<0.21 \mathrm{MJ} \cdot \mathrm{m}^{-2}$, where Es $=$ the saturation vapor pressure at the hourly average air temperature, and

$$
\operatorname{Rn}=\operatorname{Rs}(0.767)+(-0.3)
$$

for Rs $>0.21 \mathrm{MJ} \cdot \mathrm{m}^{-2}$.

Net radiation $\left(\mathrm{W} \cdot \mathrm{m}^{-2}\right)$ was converted into an equivalent depth of evaporation $(\mathrm{mm})$ by

$$
\mathrm{Rn}(\mathrm{mm})=\frac{\mathrm{Rn}\left(\mathrm{W} \cdot \mathrm{m}^{-2}\right)}{694.5(1-0.000946 \mathrm{~T})}
$$

where $\mathrm{T}=$ hourly average air temperature $(\mathrm{C})$, and the term $(1-$ $0.000946 \mathrm{~T}$ ) is the temperature coefficient of latent heat of vaporization.

The weighting function (W) was determined by

$$
\mathrm{W}=\frac{\Delta}{\Delta+\gamma}
$$

where $\Delta=$ the slope of the saturation vapor pressure curve $(\mathrm{kPa} /$ $\left.{ }^{\circ} \mathrm{C}\right)$, and $\gamma=$ the psychrometric constant $\left(\mathrm{kPa} /{ }^{\circ} \mathrm{C}\right)$.

The wind function $f(U)$ was calculated by the following two empirical equations. When $\mathrm{Rn}$ was $\leq$ zero,

$$
f(U)=0.125+0.0436\left(U_{2}\right)
$$

and when $\mathrm{Rn}>$ zero,

$$
\mathrm{f}(\mathrm{U})=0.030+0.0576\left(\mathrm{U}_{2}\right)
$$

where $\mathrm{U}_{2}=$ the average hourly wind speed measured at $2 \mathrm{~m} \mathrm{in} \mathrm{m} \cdot \mathrm{s}^{-1}$.

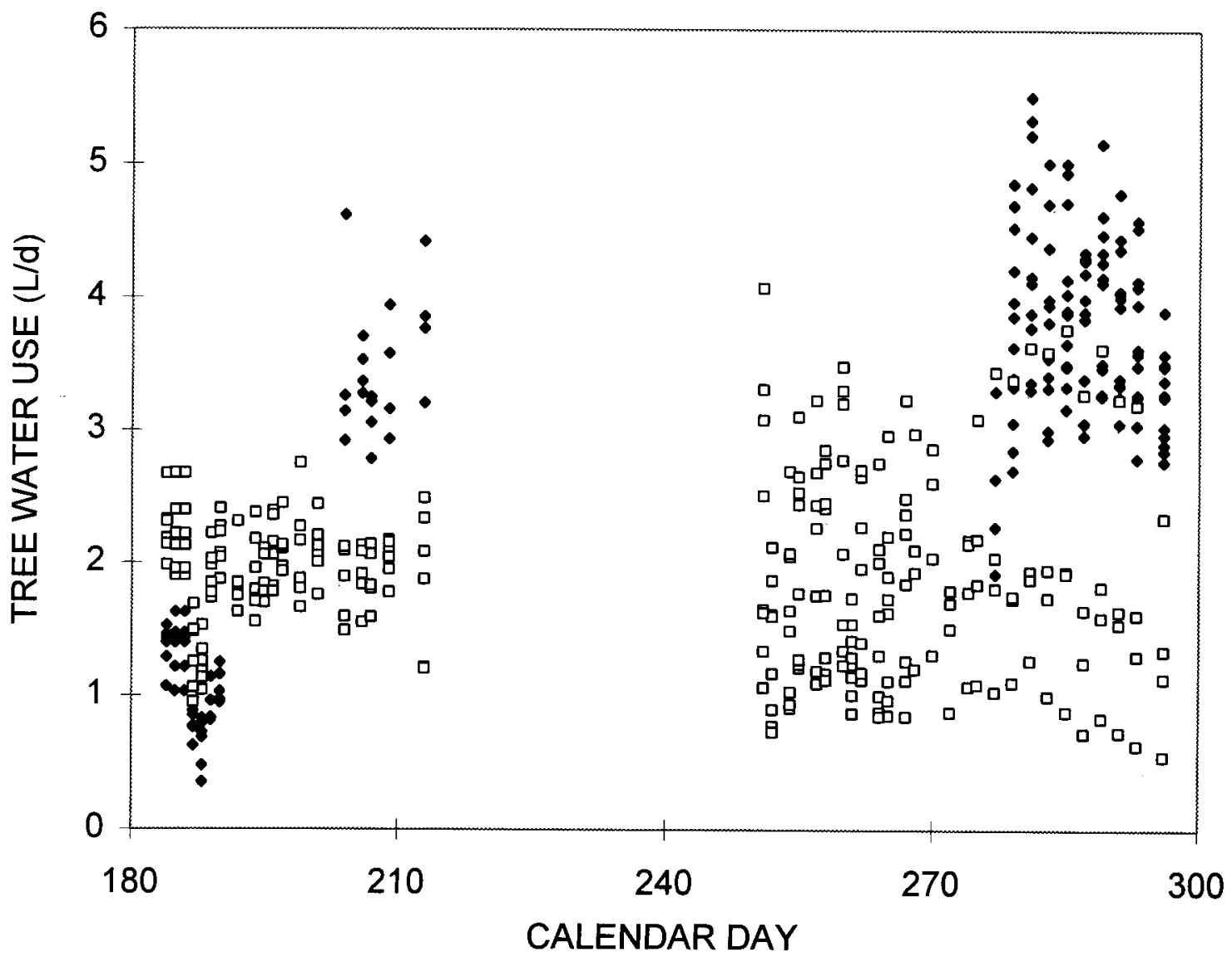

Fig. 2. Daily water use of potted oak ( $\square$ ) and mesquite ( $\bullet$. 


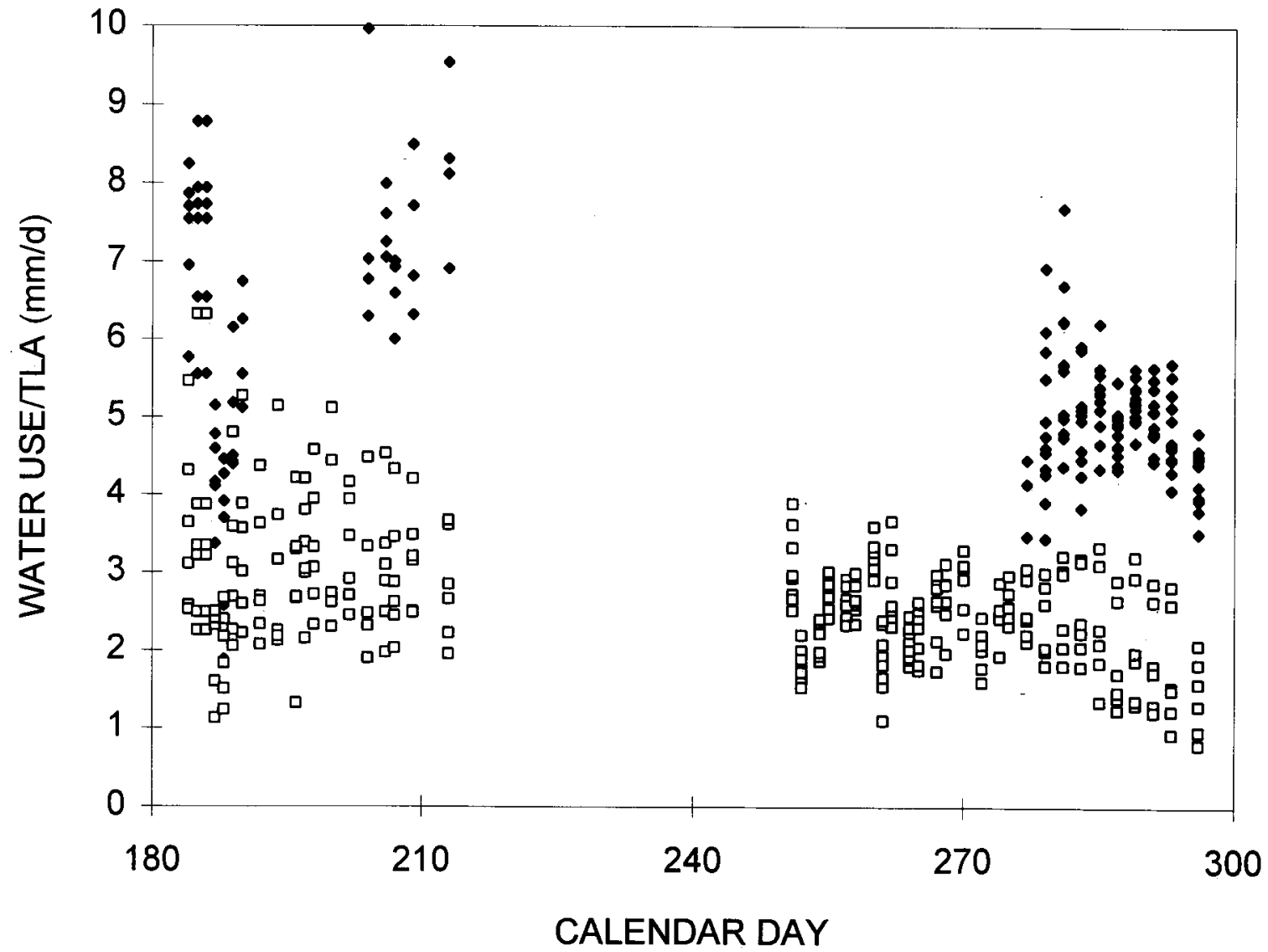

Fig. 3. Water use per total leaf area of oak $(\square)$ and mesquite $(\bullet)$.

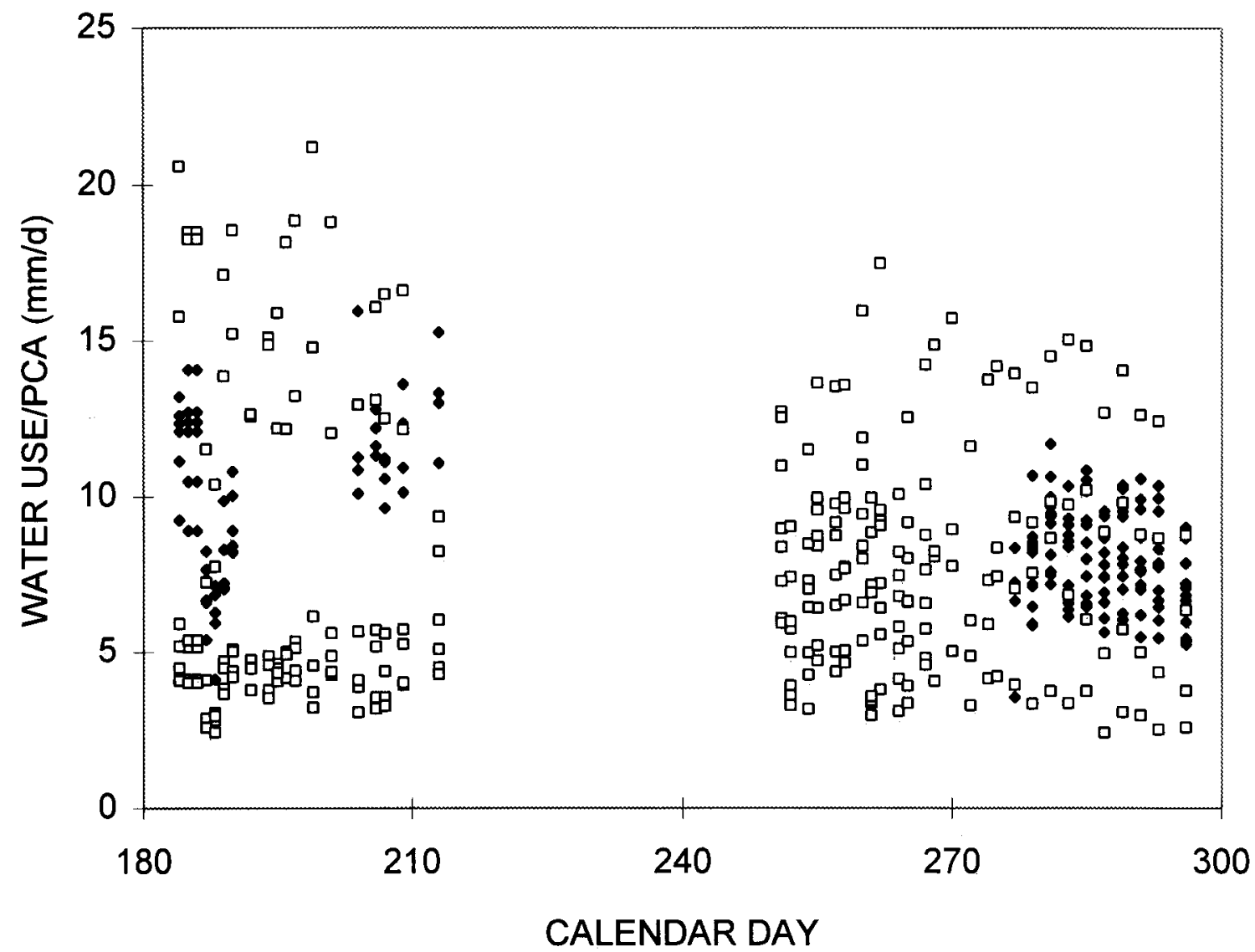

Fig. 4. Water use per projected leaf area of oak ( $\square$ ) and mesquite ( $\bullet$ ). 


\section{Results and Discussion}

The linear regressions for the mesquite and oak shoot length (SL) to leaf area (LA) calibrations are illustrated in Fig. 1. Correlation coefficients $\left(r^{2}\right)$ for the mesquite and oak regressions were 0.94 and 0.87 , respectively. However, due to the slight nonlinear trend of the oak data, a second-degree polynomial (quadratic) fit was used. The nonlinear trend is most likely the result of most of the short shoots $(<12 \mathrm{~cm})$ being counted as part of a longer shoot. The increased scatter at shoot lengths $>70 \mathrm{~cm}$ supports this conclusion. The $r^{2}$ value for the quadratic regression for the oak was 0.91 . Given these calibrations, the total leaf area of the oaks and mesquites in the field were calculated by measuring shoot lengths of each tree. Shoot lengths $>12 \mathrm{~cm}$ for the oaks were measured on 26 Sept. 1991 (CD 269) and those for the mesquites were measured on 4 Nov. 1991 (CD 308). Total leaf area of 20 trees based on the shoot length to total leaf area calibrations is listed in Table 1. The results for PCA and LAI determination for 20 trees is also given in Table 1, where LAI was determined using Eq. [2]. The average values for LAI for oak and mesquite trees were 3.0 and 1.6, respective $\mathrm{y}$.

Tree water use ranged from 0.55 to 4.07 liters $\cdot$ day $^{-1}$ for oak, and 0.35 to 5.50 liters $\cdot$ day $^{-1}$ for mesquite for the entire experiment. The large range in water use is most likely due to the range in tree size, and to weather variations during the experiment. Water use throughout the experiment is illustrated in Fig. 2. With the exception of two of the oak, and the mesquites during the first week of the experiment, normalizing by TLA appeared to reduce scatter considerably (Fig. 3). Scatter among the oaks during the first week of the experiment is most likely the result of errors in extrapolating estimates of TLA to the beginning of the experiment, since TLA was measured in the latter part of the experiment. When tree wateruse was normalized by PCA (Fig. 4), water use differences among trees were not reduced as much as by normalizing by TLA. The relatively large degree of scatter for the oaks was predominantly caused by oaks \#8 and \#12. Oak \#8 yielded relatively high wateruse values because of its relatively large LAI (Table 1). The reason for the relatively high water use by \#12 is not known.

Tree coefficients on a TLA basis are illustrated in Fig. 5. Coefficients that were greater than three standard deviations from the mean were neglected, thus eliminating any extreme outliers. For oak, this included any tree coefficients $>1.10$, which only occurred on CD 261. For mesquite, this included any tree coefficients $>1.82$, which included data from CD 187 and 213. PCAbased tree coefficients are illustrated in Fig. 6. Again, tree coefficients that were greater than three standard deviations from the mean were neglected. This included any tree coefficients $>4.17$ for the oak and 3.01 for the mesquites. These results are summarized in Table 2. The large tree coefficient values that occurred on CD 186,213 , and 261 are the result of very low average solar radiation $\left(<130 \mathrm{~W} \cdot \mathrm{m}^{-2}\right)$ on these days. Daily average solar radiation, temperature, and relative humidity during the experiment are illustrated in Fig. 7. Results indicate that isolated tree transpiration rates are proportional to solar radiation (and therefore ETo), except when solar radiation is very low and tree transpiration rates become less correlated with ETo, possibly due to the factors associated with the complex 3-D geometry of an isolated tree. Results of tree coefficient determination indicate that under nonlimiting conditions, the mesquites used $50 \%$ more water than the oaks on a TLA basis, and $13 \%$ more water on a PCA basis.

In general, it was more difficult to estimate PCA than TLA, and there was greater error in estimating PCA than TLA. It was easier

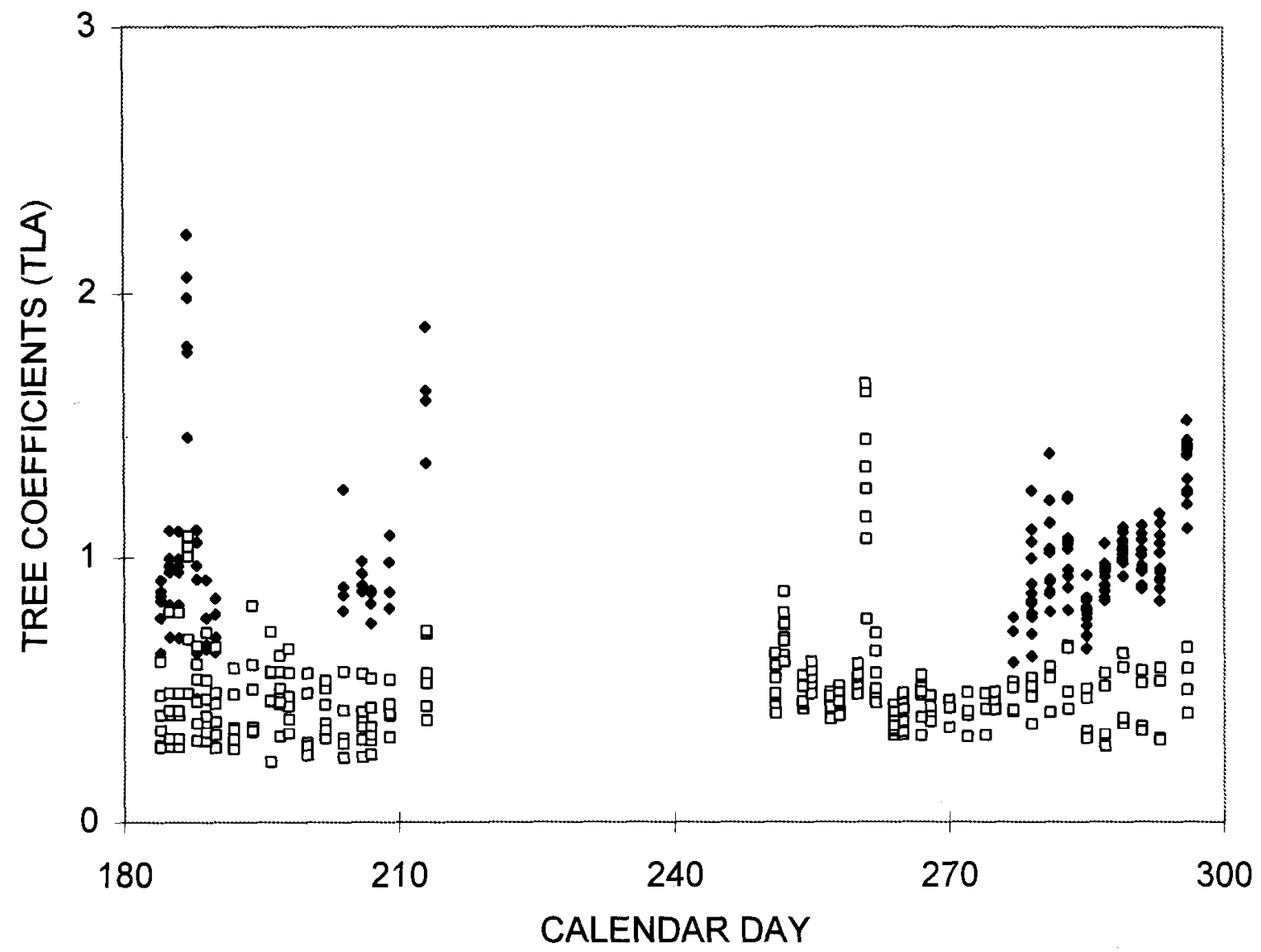

Fig. 5. TLA-based tree coefficients $\left(\mathrm{K}_{\text {tree }}\right)$ for oak $(\square)$ and mesquite $(\bullet)$. 


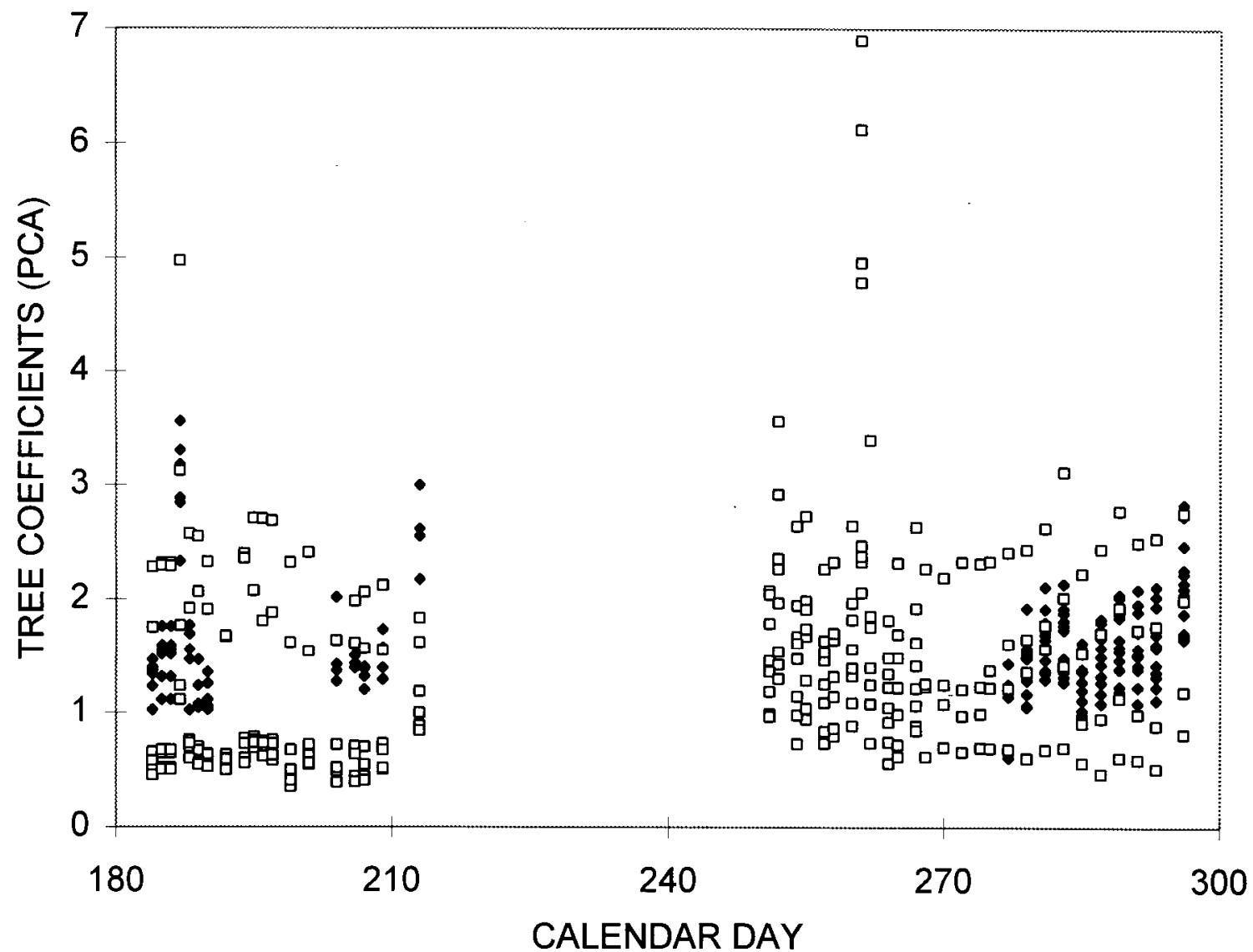

Fig. 6. PCA-based tree coefficients $\left(\mathrm{K}_{\text {trce }}\right)$ for oak $(\square)$ and mesquite $(\bullet)$.

Table 2. Statistics of the dimensionless tree coefficient, $\mathrm{K}_{\text {tree }}$.

\begin{tabular}{|c|c|c|c|c|}
\hline & \multicolumn{2}{|c|}{$\mathrm{Oak}$} & \multicolumn{2}{|c|}{ Mesquite } \\
\hline & T L A & PCA & TLA & PCA \\
\hline$\overline{\text { Mean }}$ & 0.48 & 1.36 & 0.97 & 1.56 \\
\hline S D & 0.14 & 0.75 & 0.22 & 0.41 \\
\hline $\mathrm{n}$ & 263 & 265 & 167 & 168 \\
\hline M ax & 1.08 & 4.97 & 1.80 & 3.00 \\
\hline M i n & 0.23 & 0.35 & 0.47 & 0.61 \\
\hline
\end{tabular}

to estimate the PCA of oaks than mesquites, because the PCA of oaks could be approximated by a circle, while the PCA of mesquites was usually irregular in shape. However, even assuming a circular PCA for the oaks, a $10 \%$ error in measuring the radius of PCA would result in a $20 \%$. error in PCA. Better estimates of PCA most likely would have improved the PCA normalizations. Accurate estimates of TLA were dependent on the accuracy of the shoot length to TLA calibration. However, if a reliable calibration is available, then it is fairly simple to obtain accurate estimates of TLA by measuring shoot lengths.

Based on the results of this experiment, daily tree water use can be predicted by use of a tree coefficient, $\mathrm{K}_{\text {tree }}$. The $\mathrm{K}_{\text {tree }}$ values were fairly consistent throughout the experiment, indicating that one value of $\mathrm{K}_{\text {tree }}$ is appropriate for an entire growing season for these two species. The mesquites yielded a larger value of $\mathrm{K}_{\text {tree }}$ than the oaks, indicating that the mesquites, normally considered a xeric species, used more water than the oaks, normally considered a mesic species, under nonlimiting water conditions. In fact, on a TLA basis, the mesquites used twice as much water as the oaks. These results illustrate the need to reevaluate existing lists of drought tolerant and low-water-use trees.

The PCA-based $\mathrm{K}_{\text {rree }}$ values of 1.36 and 1.56 for the oaks and mesquites, respectively, are much larger than the $\mathrm{K}_{\text {tree }}$ values of 0.40 reported by Garbesi (1992). However, these coefficients are for potted, relatively small trees, which were probably transpiring fully throughout their relatively open canopies. In addition, these trees had large spacing between them and were surrounded by bare soil, which provided strong advective conditions. These factors would tend to yield higher $\mathrm{K}_{\text {tree }}$ values than for trees under more natural conditions. Garbesi (1992) reported coefficients for trees that were simply maintained and were not fully transpiring, thus violating the definition of the crop coefficient and resulting in coefficient underestimations. However, landscape trees are more likely to be waterstressed than a crop. Therefore, it would probably be useful to redefine the tree coefficient with an additional factor that accounts for reduced water availability. This would enable the application of the tree coefficient concept to determination of isolated tree water use under water-limiting conditions, such as described by Garbesi (1992).

Future work should include validation of the tree coefficients for potted as well as out-planted trees, determination of tree coefficients for other species, and reevaluation of lists of droughtresistant vs. low-water-use trees.

\section{Literature Cited}

Ceulemans, R., R.F. Stettler, T.M. Hinckley, and J.G. Isebrands. 1989. Crown architecture and leaf demography in intensively cultured hybrid Populus clones. J. Worrall, J. Loo-Dinkins, and D.P. Lester (eds.). Physiology and genetics of reforestation. Univ. British Columbia, Canada.

Costello, L. R., N.P. Matheny, and J.R. Clark. 1992. Estimating water 


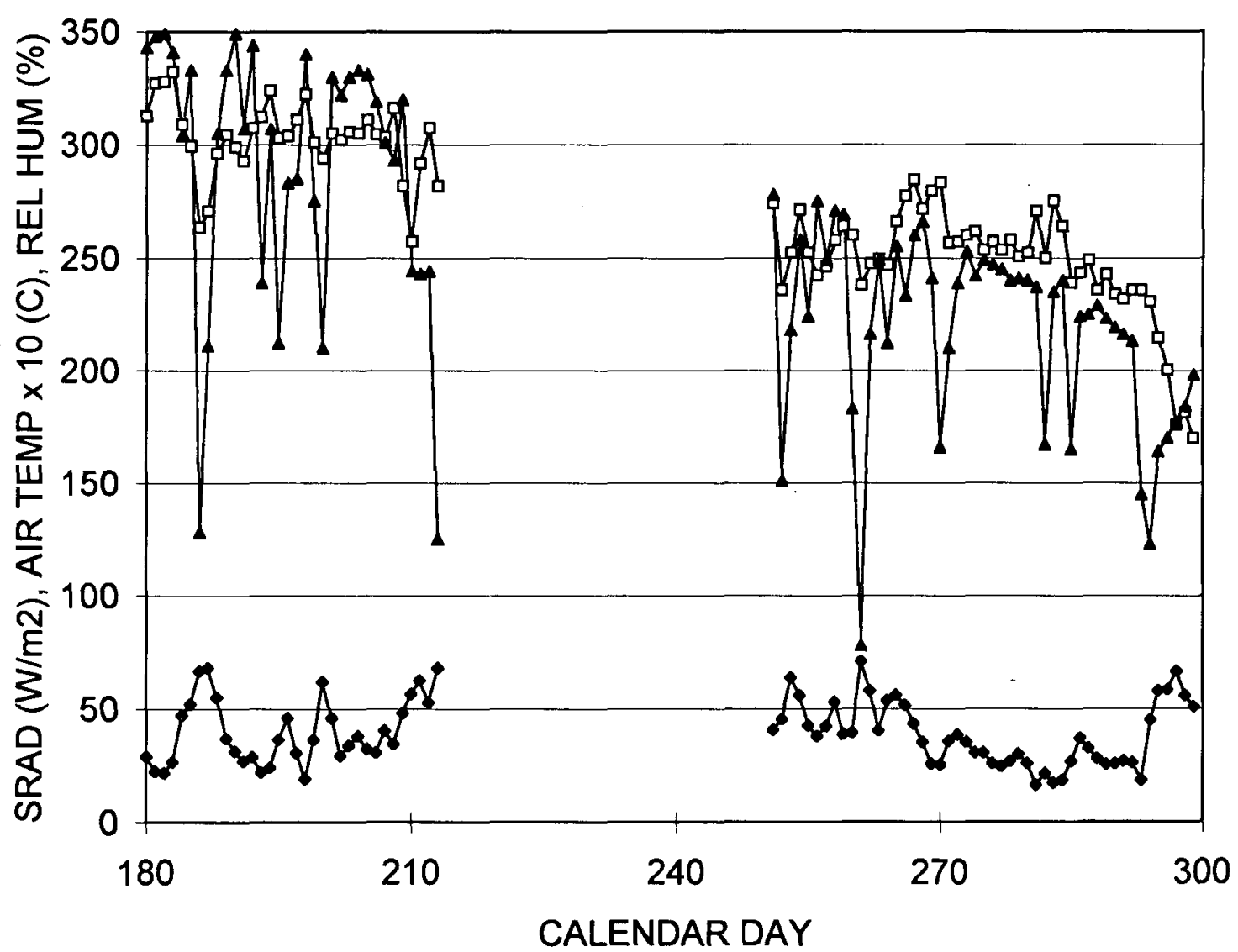

Fig. 7. Daily average solar radiation $(\boldsymbol{\Delta})$ in $\mathrm{W} \cdot \mathrm{m}^{-2}$, daily average air temperature $\times 10(\square)$ in ${ }^{\circ} \mathrm{C}$, and daily average relative humidity $(\bullet)$ in percent during the experiment.

requirements of landscape plantings: The landscape coefficient method. Univ. of California Leaflet 21493. Univ. of California, Div. of Agr. and Natural Resources.

Denmead, O.T. 1984. Plant physiological methods for studying evapotranspiration: Problems of telling the forest from the trees. Agr. Water Mgt 8:167-189.

Desai, J.B. 1981. Water requirements of urban plants. MS thesis. Univ. of Arizona.

Doorenbos, J. and W.O. Pruitt. 1977. Guidelines for predicting crop water requirements. Irr. and Drainage Paper 24. 2nded., FAO, Rome.

Fritschen, L. J., J. Hsia, and P. Doraiswamy. 1977. Evapotranspiration of a Douglas Fir determined with a weighing lysimeter. Water Resources Re. 13:145-148.

Garbesi, K. 1992. Estimating water use by various landscape scenarios, p. 157-172. Cooling our communities, A guidebook on tree planting and light-colored surfacing. Lawrence Berkeley Laboratory and U.S. Environ. Protection Agency.

Grip, H., S. Halldin, P-E. Jansson, A. Lindroth, B. Noren, and K. Perttu. 1979. Discrepancy between energy and water balance estimates of evapotranspiration. Comparison of forest water and energy exchange models. Intl. Soc. Ecol. Modelling, Copenhagen, p. 237-255.

Hoffman, G. J., J. D. Oster, and W. J. Alves. 1982. Evapotranspiration of mature orange trees under drip irrigation in an arid climate. Trans. Amer. Soc. Agr. Eng.

Landsberg, J.J. and R. McMurtie. 1984. Water use by isolated trees. Agr. Water Mgt. 8:223-242.
Leuning, R. and I. J. Foster. 1990. Estimation of transpiration by single trees: Comparison of a ventilated chamber, leaf energy budgets and a combination equation. Agr. For. Meteorol. 51: 63-86.

McGinnies, R. and J. Arnold. 1939. Relative water requirements of Arizona range plants. Arizona Agr. Expt. Sta. Tech. No 80: 165-246.

McPherson, E.G. 1991. Economic modeling for large-scale urban tree plantings, p. 349-369. In: E. Vine, D. Crawley, and P. Centolella (eds.). Energy efficiency and the environment: Forging the link. Amer. Council Energy-efficient Econ., Washington, D.C.

Middleton, J. E., E.L. Proebsting, and S. Roberts. 1979. Apple orchard irrigation by trickle and sprinkler. Trans. Amer. Soc. Agr. Eng.

Monteith, J.L. 1965. Evaporation and the environment. Symp. Soc. Expt. Biol. 19:205-234.

Snyder, R. L., B.J. Lanini, D.A. Shaw, and W.O. Pruitt. 1989. Using reference evapotranspiration and crop coefficients to estimate crop evapotranspiration for trees and vines. Univ. of California Leaflet 21428, California Dept. of Water Resources.

Steinberg, S. L., C. H. M. van Bavel, and M. J. McFarland. 1989. A gauge to measure mass flow rate of sap in stems and trunks of woody plants. J. Amer. Soc. Hort. Sci. 114:466-472.

Tan, C.S. and R.E.C. Layne. 1981. Application of a simplified evapotranspiration model for predicting irrigation requirements of peach. HortScience 16:172-173.

Worthington, J. W., M.J. McFarland, and P. Rodrique. 1984. Water requirements of peach as recorded by weighing lysimeters. HortScience 19:90-91. 